\title{
Model-based Instruction as an Activity in Teaching a Pharmaceutics Course
}

\author{
May Almukainzi \\ Department of Pharmaceutical Sciences, College of Pharmacy, Princess Nourah bint Abdulrahman University, \\ Riyadh, SAUDI ARABIA.
}

\begin{abstract}
Objectives: Pharmaceutics is the core component of pharmacy education; the course helps pharmacy students to understand the influence of drugs' physicochemical characteristics and manufacturing parameters on therapeutic performance. Although they are important, pharmaceutics concepts can be "dry," especially since many pharmacy schools teach pharmaceutics using the traditional lecture-only format. Therefore, activities through which students can perceive the relevance of the subject to clinical applications and that keep learners engaged in their classes are very much in demand. Methods: In this study, the incorporation of model-based instruction (MBI) in teaching a pharmaceutics course was explored, and the reasons for integrating this type of model were discussed. We presented a case study involving students transferring scientific knowledge to tactile models. The students' perception of the usefulness of this activity was evaluated. Results: The open-ended questions in the survey showed that the models helped learners to understand the content and enjoy the class. Conclusion: The study provided examples of interactive, simple, easy, and inexpensive $\mathrm{MBI}$, where students could demonstrate their content understanding and their skills. The process of creating and evaluating models transforms the student class experience from static to dynamic and may help students achieve profound and long-lasting learning.
\end{abstract}

Key words: Simulation and education, Modelling and education, Physical models and teaching, Small-group activities, PharmD, Pharmacy education.

\section{INTRODUCTION}

Pharmaceutics is a subdivision of pharmaceutical sciences; it describes the formulations, perpetrations, manufacturing processes, and parameters of different drugs and their dosages. The pharmaceutics course is one of the core components of pharmacy education, and it is taught in almost all pharmacy schools worldwide. The course helps pharmacy students to understand the influence of drugs' physicochemical characteristics and manufacturing parameters on therapeutic performance. ${ }^{1,2}$ Although they are important, pharmaceutics concepts can be "dry", especially since many pharmacy schools teach pharmaceutics using the traditional lecture-only format. ${ }^{3-6}$ Therefore, activities through which students perceive the relevance of the subject to clinical applications and that keep learners engaged in classes are very much in demand. Studies have showed that using visual aids improves students' understanding and retention, even for complex and cumbersome topics. $4,6,7$ Therefore, some universities have implemented laboratory exercises to illustrate physical pharmaceutical concepts and compounding techniques. Although lab exercises have a significant impact on understanding theoretical material, the bench space that is needed to accommodate a class in a pharmacy compounding laboratory can minimize the effectiveness of these exercises. ${ }^{6}$

To allow the students to visualize drug products, course instructors usually bring drug dosage forms as finished product
Submission Date: 09-08-2020; Revision Date: 02-02-2021; Accepted Date: 12-06-2021

DOI: 10.5530/ijper.55.3.136 Correspondence: Dr. May Almukainzi

Department of Pharmaceutical Sciences, College of Pharmacy, Princess Nourah bint Abdulrahman University, Riyadh-Box 84428, SAUDI ARABIA. Phone no: +966118239613 Email id: mkalmukainizi@pnu. edu.sa

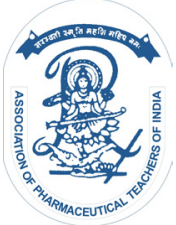

www.ijper.org 
items to class as examples of the related discussion topics. However, with this approach, students see only the products in their final shape and miss seeing the manufacturing steps. Additionally, passing the products around the class tends to disrupt the class, and students often give the products only a glance. ${ }^{4}$

Modelling is a visual aid that can be used in classrooms. It can be achieved by producing or building structural analogues to real scenarios, which can be two-dimensional (drawings, diagrams or maps), three-dimensional (concrete or analogical), or virtual (simulations). ${ }^{8-10}$ Model-based instruction (MBI) involves students building and evaluating models as a means to learn the content. ${ }^{11,12}$ The assumptions of model-based learning are based on mental models theory. ${ }^{13,14}$ This theory describes how individuals can learn new information by structuring mental models from the available knowledge (preconceptions). ${ }^{14,15}$ Instructors need to make sure that students' mental models are correctly related to the science; therefore, modelling created by students is a way to externalize their mental models as a reflection of their learning knowledge. ${ }^{14,16}$ It can help instructors to provide students with needed feedback and correct any misunderstandings. It can also promote multiple dimensions of learning, content understanding, and skills development. ${ }^{17,18}$ Limited practical resources and studies exist to help instructors incorporate MBI into the classroom. A recent study outlined a teaching guide for integrating modelling into biology classrooms. ${ }^{19}$ The guide offered different model types that are commonly used in teaching biology; however, the concept can be extended to other subjects such as pharmaceutics. This study aimed to explore incorporating MBI as learning activities in teaching a pharmaceutics course.

\section{MATERIALS AND METHODS}

The Principles of Pharmaceutics: Dosage Forms and Stability (PHS 321) is a required 3-credit course for thirdyear doctor of pharmacy (PharmD) students at Princess Nourah bin Abdulrahman University. Lectures are used to introduce concepts and principles in the course. Students then are expected to apply their knowledge through a variety of activities, discussion boards, and examinations. The study was conducted over a period of three months 1/9/2019-1/12/2019.

\section{Class setting}

The merits of the proposal and its alignment with national regulations were evaluated, and the study received "exempt" status from the Institutional Review Board (Registration Number 20-0140) of Princess
Noura University, Riyadh, Saudi Arabia. An online survey was submitted at the beginning of the class. The survey contained questions about the students' names, hobbies, and skills. Five small groups consisting of (twothree) students were assigned based on the results of the survey. Students who had mastered the same skills were in the same group. For example, students who had mastered crafting were in the same group, and those who had mastered video making and technology were in another group. Each group was responsible for presenting one model. Although the skills required for building models are not inherent and can be developed with practice, this approach was adopted to engage the students and so that they would enjoy designing the models.

\section{Model selection}

Five important topics were chosen: 1) Wet granulation as a finished product and as an intermediate stage for other oral dosage forms, 2) Suppositories as a dosage form, 3) Disintegration testing as quality-control testing for oral dosage forms, 4) Percolation as a method for the extraction of liquid drugs and 5) Good manufacturing practices (GMPs) that are required for a drug manufacturer. After providing the lectures to the class, the instructor gave the students at least three weeks to prepare their models. The instructor guided each model, and feedback was provided individually for each group by meeting with them at least twice. The feedback addressed the group's content knowledge and modelling skills.

\section{Student assessments}

An interactive class was designed in which each group presented their model on a table with a tag number. Each group stood near their model and discussed the modelling process and the materials used for building it. The rest of the students walked through each station, and the course instructor answered any questions or redirected groups if necessary. This system allowed the students to learn from each other and fill in any knowledge gaps. Immediately after the class, a survey was sent to the students, and they were allowed to complete the survey online or on paper. The survey consisted of open questions to identify what each model number was representing. Students' satisfaction with the modelling class activity was also assessed through the survey.

\section{RESULTS}

The first group made simple granules from paste and then sieved and coated them by spraying them with different colours. Some of the granules were then used 


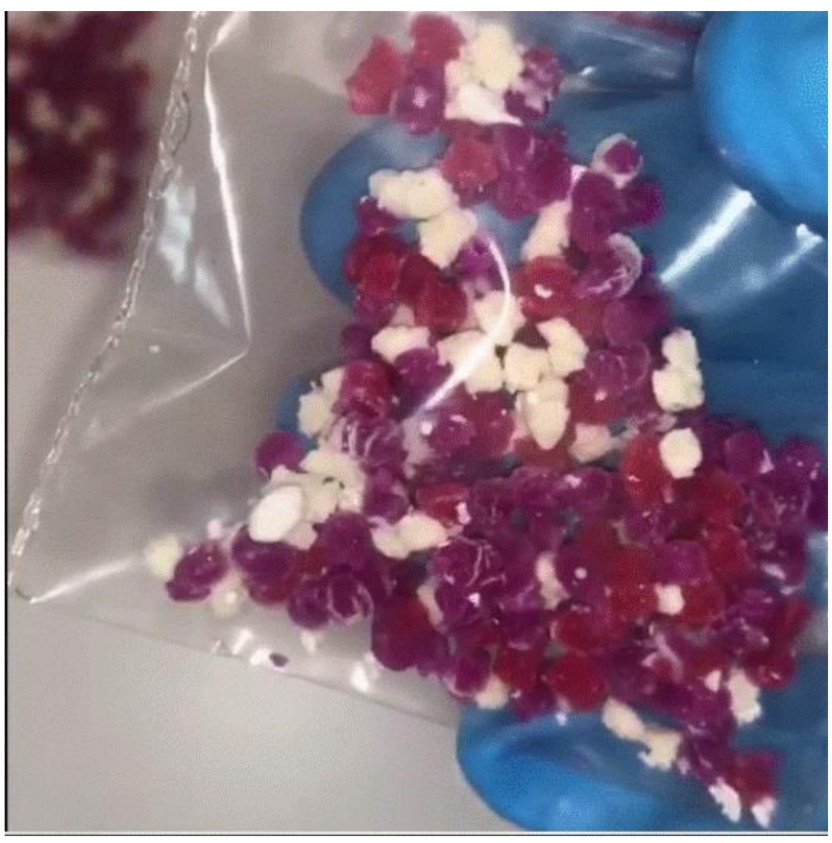

Figure 1(a): Examples of the granules model made by students.

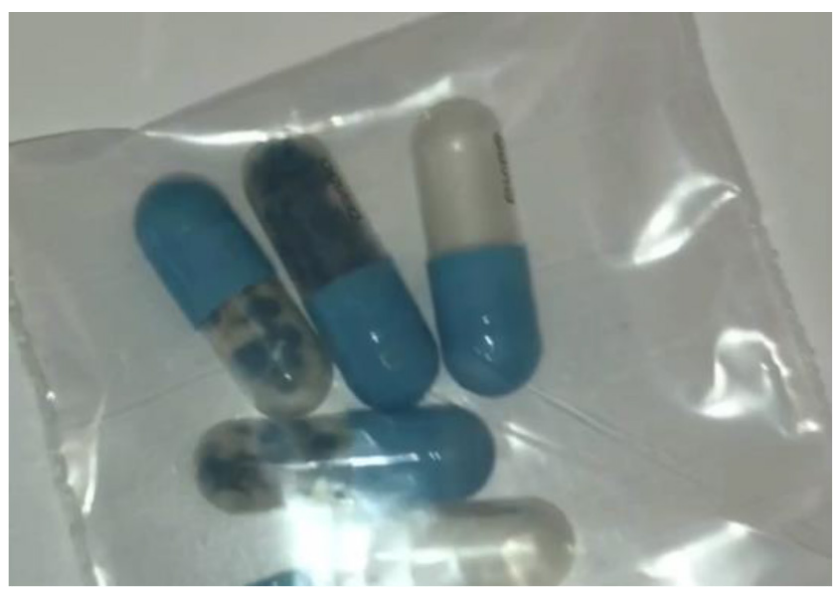

Figure 1(b): Examples of the granules model made by students.

to fill empty shell capsules or compressed as tablets using a simple mould. Each step represented a manufacturing stage and was presented in separate plastic bags (Figure $1 \mathrm{a}, \mathrm{b})$.

The second group created disintegration testing by having 6 glass tubes inside a one letter container using a simple mechanism to move the basket shaft. Each component's characteristics were selected based on the United States Pharmacopeia (USP) disintegration testing requirements. Students presented how disintegration times differ for different dosage forms (e.g., fast disintegrating tablets and immediate-release tablets).

The simple suppositories were made using oils and waxes in a simple mould. The last group percolated herbs and coffee and diluted them with water to represent percolated drug solutions.

The video-maker group visited a drug manufacturer and made a 5-min film about the required GMPs in drug manufacturing. The video contained photos that were taken from a real visit to one of the local manufacturers. Students narrated the video using their voices and text with some sound effects. Then, they presented the video on a tablet computer on their table.

In total, 54 surveys were completed by the students and returned to the faculty. All students who were walking through the room were able to identify the represented models by answering questions in the survey. The open-ended questions in the survey showed that all students enjoyed the activities, and their feedback was positive. The students commented on how they could understand many concepts using simple tools. The last question in the survey asked the students to choose the model that best represented the real scenario. Most of the comments supported the tactile visualizations of physical models (as in the granulation, suppositories and disintegration testing models), whereas only a few of them selected the videos.

\section{DISCUSSION}

Modelling allows the representation of complex ideas through simple demonstrations, which can be achieved with conceptual models of processes and pathways, simulations, or physical models. Simulation software is used widely in pharmaceutical sciences to predict and explain theories such as in vivo drug absorption ${ }^{20-22}$. and in vitro lab testing. ${ }^{23}$ In health education, simulation software is used by instructors to mimic patients' cases and clinical scenarios. ${ }^{24}$ For instruction in pharmacy courses, the Accreditation Council for Pharmacy Education (ACPE) board approved a policy to allow simulations to account for up to $20 \%$ of the introductory pharmacy practice experience (IPPE) time. ${ }^{25,26}$ The current applications of simulation software are restricted to mimicking clinical cases. The uses of simulation software in a pharmaceutics course, which is specially designed for pharmacy students, are very limited. This may explain the limited simulation software applications in pharmacy education compared to other health disciplines such as nursing and medical education. ${ }^{25}$ Although simulation software and technologies are great tools in health profession education, they have some significant limitations. Primarily, they can reduce the physical interactions between instructors and students. Additionally, incorporating technology into the curriculum can have high costs for colleges and schools. ${ }^{27}$ An individual 
simulator may cost the institution around $\$ 30,000$ on average, which does not include maintenance, training, and technical support fees. ${ }^{24,25}$ As well, extensive time and commitment are required to develop and implement such technologies. ${ }^{24}$

Our study provides examples of interactive, simple, easy, and in expensive MBI applications, where students can show their content understanding and their skills. By having the students create models in pharmaceutics courses; instructors can self-direct learners in robust cognitive and social tasks. This approach provides instructors with insight into student thinking and allows students to improve their knowledge through different modes. ${ }^{28,29}$ The models that are created by students can enhance the students' critical thinking and promote deep and long-lasting learning by engaging them in the learning process. ${ }^{28}$ This is an important consideration since some pharmaceutics courses are generally taught in the early stages of number of PharmD programme curriculum and may gradually be forgotten by the time student's graduate. Through modeling, students can advance their understandings of some physical pharmacy concepts such as solubility, dissolution, interfacial phenomena. Moreover, MBI can also be helped to better understanding pharmaceutical formulation, manufacturing, and dispensing.

A similarapproach was applied in teaching pharmaceutical care services management and presented in a published study. ${ }^{30}$ The study showed an example of a group activity to pharmacy master's program where the student had to transform their classroom into a pharmacy with displays, a counter..$^{30}$ Instructors are expected to understand the different knowledge, skills, equipment, and time required of students for implementing MBI in course activities, so a model's full perception can be reached.

Studies have shown that modelling is particularly suited for small-group work, as it permits students to communicate more during the modelling process. ${ }^{10,19}$ As in our study, using a small group in MBI enhances the discussion among the group when selecting the components that are required to demonstrate the model. Such interactions not only facilitate the selection of the representation mode but also increase the likelihood that students will understand the knowledge through self and peer learning. Small group in MBI also allows the instructor to provide rapid and specific feedback to encourage better modelling and conceptual understanding of the content. Presenting their model to the rest of the class enables the students in a group to learn, interpret, analyse, and utilize the collective expertise of their peers. ${ }^{31}$
As the teaching is shifting to online sitting during the current state of the COVID-19 pandemic, the modelling approaches can be a great and unique activity to applied with some relevant modification for the online setting. Researchers have shown the need for such an approach in minimizing the impact of COVID-19 pandemic on the education..$^{32}$ Planning sufficient time for MBI activities is essential for practice and feedback that are aligned with learning goals and outcomes. Further research including constructed assessments and statistical analysis of the usefulness of MBI in online setting and its impact on long-term memory is required.

\section{CONCLUSION}

MBI in a pharmaceutics course engages students by involving them in studying, building, and evaluating models, and it allows students to learn the content of and develop skills within the discipline. This study demonstrates examples of such models that transfer a course's scientific knowledge into simple representations that can be shared with and evaluated by peers. The process of creating and evaluating models transforms the student experience from static to dynamic. This may have the potential to change students' views of the pharmaceutics course and help students achieve profound and long-lasting learning.

\section{ACKNOWLEDGEMENT}

This research was funded by the Deanship of Scientific Research at Princess Nourah bint Abdulrahman University through the Fast-track Research Funding Program.

\section{CONFLICT OF INTEREST}

The author declares no conflict of interest.

\section{ABBREVIATIONS}

MBI: Model-based Instruction; GMPs: Good manufacturing practices; USP: United States Pharmacopeia; ACPE: Accreditation Council for Pharmacy Education; IPPE: Introductory pharmacy practice experience; PharmD: Doctor of pharmacy.

\section{REFERENCES}

1. Almukainzi M, Alobaid R, Aldosary M, Aldalbahi $Y$, Bashiri M. Investigation of the effects of different beverages on the disintegration time of over-thecounter medications in Saudi Arabia. Saudi Pharm J. 2021. doi:https://doi. org/10.1016/j.jsps.2021.04.032.

2. Romero RM, Eriksen SP, Haworth IS. Quantitative assessment of assisted problem-based learning in a pharmaceutics course. Am J Pharm Educ. 2010;74(4). 
3. Das NG, Das SK. An Approach to Pharmaceutics Course Development as the Profession Changes in the 21st Century. Pharm Educ. 2002;1(3):159-71.

4. Fox LM, Pham KH, Dollar M. Using interactive digital images of products to teach pharmaceutics. Am J Pharm Educ. 2007;71(3).

5. Podczeck F. Pharmaceutics teaching and the pharmaceutical industry. Pharm Technol Eur. 2008;20(7):50.

6. Yellepeddi VK, Roberson C. The use of animated videos to illustrate oral solid dosage form manufacturing in a pharmaceutics course. Am J Pharm Educ. 2016;80(8).

7. Curley LE, Wu Z, Svirskis D. Using technology in pharmacy education: Pharmacy student performance and perspectives when visual aids are integrated into learning. F Front. Pharmacol 2018;9:1062.

8. Brooks $C$, Thompson C. Predictive modelling in teaching and learning. Handb Learn Anal. 2017;61-8. doi:10.18608/hla17.005.

9. Gilbert JK, Justi R. Models and Modeling in Science Education. Springer International Publishing. 2016.

10. Vadlapatla R, Kaur S, Zhao Y. Evaluation of student perceptions of concept mapping activity in a didactic pharmaceutics course. Currents in Pharmacy Teaching and Learning. Curr Pharm Teach Learn. 2014;6(4):543-9.

11. Buckley BC. Model-Based Teaching BT - Encyclopedia of the Sciences of Learning. In Springer US. 2012;2312-5. doi:10.1007/978-1-4419-14286 690.

12. Model-Centered Instruction BT - Encyclopedia of the Sciences of Learning. in (ed. Seel, N. M.) 2315 (Springer US, 2012). doi:10.1007/978-1-4419-1428$6 \_4975$.

13. Yuksel T, Rebello NS, Bryan LA. Model-based inquiry vs . Traditional computer simulation-based instruction: Which can better help students construct the quantum-mechanical model of an atom? Model-based inquiry vs . Traditional computer simulation-based instruction: Which Can Better H. 2018. doi:10.1119/perc.2017.pr.109.

14. Hanke U. Realizing Model-Based Instruction BT-Understanding Models for Learning and Instruction. Springer US. 2008;175-86. doi:10.1007/978-0-38776898-4_9.

15. Dagnew A, Endris A, Studies C. Title??? International Journal of Learning and Teaching. 2020;12:72-85.

16. Durak B, Topçu, M. S. Socio-Scientific Issues and Model-Based Learning. In Socioscientific Issues-Based Instruction for Scientific Literacy Development. 2021;279-97. doi:10.4018/978-1-7998-4558-4.ch010.

17. Schwarz CV, et al. Developing a learning progression for scientific modeling: Making scientific modeling accessible and meaningful for learners. J Res Sci Teach. 2009;46(6):632-54.
18. Louca L, Zacharia Z. Modeling-based learning in science education: Cognitive, metacognitive, social, material and epistemological contributions. Educ Rev. 2011.

19. Wilson KJ, Long TM, Momsen JL, Speth BE. Modeling in the Classroom: Making Relationships and Systems Visible. CBE Life Sci Educ. 2020;19(1):fe1.

20. Almukainzi M, Gabr R, Abdelhamid G, Löbenberg R. Mechanistic understanding of the effect of renal impairment on metformin oral absorption using computer simulations. J Pharm Investig. 2017;47(2):151-61.

21. Almukainzi $M$, Jamali $F$, Aghazadeh-Habashi A, Löbenberg R. Disease specific modeling: Simulation of the pharmacokinetics of meloxicam and ibuprofen in disease state vs. healthy conditions. Eur J Pharm Biopharm. 2016;100:77-84.

22. Bolger MB, Macwan JS, Sarfraz M, Almukainzi M, Löbenberg R. The irrelevance of in vitro dissolution in setting product specifications for drugs like dextromethorphan that are subject to lysosomal trapping. J Pharm Sci. 2019;108(1):268-78.

23. Almukainzi $\mathrm{M}$, Okumu $\mathrm{A}$, Wei $\mathrm{H}$, Löbenberg R. Simulation of in vitro dissolution behavior using DDDPlus ${ }^{\mathrm{TM}}$. AAPS Pharm Sci Tech. 2015;16(1):217-21.

24. Benedict N, Schonder K. Patient simulation software to augment an advanced pharmaceutics course. Am J Pharm Educ. 2011;75(2).

25. Lin K, Travlos DV, Wadelin JW, Vlasses PH. Simulation and introductory pharmacy practice experiences. Am J Pharm Educ. 2011;75(10):209.

26. ACPE. Accreditation Council for Pharmacy Education Policies and Procedures for Acpe Accreditation of Professional Degree Programs. 2018.

27. Fusco NM, Foltz-Ramos K. Impact of Pharmacy Student Observation Versus Active Participation in an Interprofessional Simulation. Am J Pharm Educ. 2020;84(1).

28. Dauer JT, Long TM. Long-term conceptual retrieval by college biology majors following model-based instruction. J Res Sci Teach. 2015;52(8):1188-206.

29. Wilson KJ, Long TM, Momsen JL, Speth EB. Modeling in the classroom: Making relationships and systems visible. CBE Life Sci Educ. 2020;19(1):fe1.

30. Werf JJVD, Dekends-Konter J, Brouwers JR. A new model for teaching Pharmaceutical Care Services Management. Pharmacy Education. 2004;4(4).

31. Sims, P. Utilizing the Peer Group Method with Case Studies to Teach Pharmaceutics. Am J Pharm Educ. 1994;58(1):78-81.

32. Currie CS, Fowler JW, Kotiadis K, Monks T, Onggo BS, Robertson DA, Tako AA. How simulation modelling can help reduce the impact of COVID-19. Journal of Simulation. 2020;14(2):83-97.

\section{SUMMARY}

The pharmaceutics course is the core component of pharmacy education, as it helps pharmacy students to understand the influence of drugs' physicochemical characteristics and manufacturing parameters on therapeutic performance. Although pharmaceutics courses are important for pharmacy students, some concepts can be "dry", especially if teaching occurs using the traditional lecture-only format. Therefore, simulations using software and technology tools are used in some universities. However, simulations have some significant limitations, as they can reduce the physical interaction between instructors and students, and they can carry high costs related to incorporating technology into the curriculum. Very limited studies have investigated the application of modelling in teaching the pharmaceutics course. This research article highlights the usefulness of modelling in teaching pharmaceutics courses, and demonstrates examples of interactive, simple, easy, and inexpensive model-based instruction, where students can show their content understanding and their skills. By having the students create models, instructors can self-direct learners in robust cognitive and social tasks. This process provides instructors with insight into student thinking and allows students to improve their knowledge through different modes. The models created by students can enhance students' critical thinking and promote deep and long-lasting learning by engaging students in the learning process. 


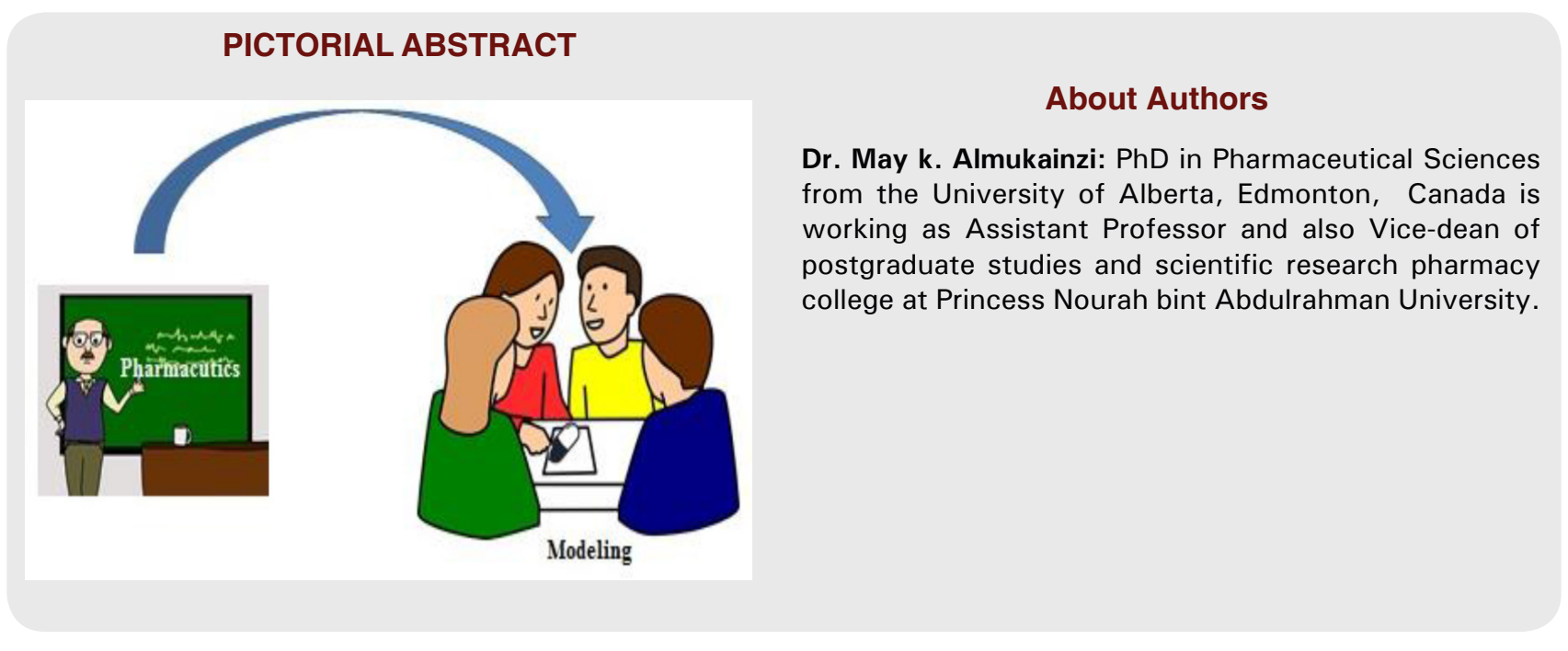

Cite this article: Almukainzi M. Model-based Instruction as an Activity in Teaching a Pharmaceutics Course Indian $\mathrm{J}$ of Pharmaceutical Education and Research. 2021;55(3):649-54. 